\title{
Correlation of physics and chemical factors on phytoplankton distribution pattern in North Sunter Reservoir, Jakarta
}

\author{
Claudia Juliastutie ${ }^{1}$, Astri Rinanti ${ }^{1}$, and Diana Hendrawan $^{1 *}$ \\ ${ }^{1}$ Trisakti University, Environmental Engineering, Faculty of Landscape Architecture and Environmental Technology, Jakarta, 11440 , \\ Indonesia
}

\begin{abstract}
This study aims to determine the condition of the waters of the North Sunter Reservoir through the distribution pattern of phytoplankton and the influence of the physical and chemical aspects of the waters on the presence of phytoplankton. The study was conducted from August 2017 to January 2018 with 12 sampling points. Phytoplankton sampling was performed vertically on two different segments each with a depth range of 0-1.9 meters and 1.9-3.9 meters using planktonet number 25. Research shows that phytoplankton can live on the bottom of the reservoir with little sunlight conditions due to the large concentration of nitrate and phosphate. The abundance of phytoplankton in segment 1 (7,104-219,820 cells/L) and segment 2 (9,771-132,313 cells/L) consisted of 4 phyla namely Cyanophyta (8 genera), Chrysophyta (10 genera), Chlorophyta (16 genera), and Euglenophyta (4 genera). The index of the diversity of phytoplankton in segment $1(1.22-2.39)$ and segment $2(1.14-2.13)$, everness index on segment 1 (0.47$0.85)$ and segment 2 (0.45-0.85), dominance index in segment 1 (0.12-0.76) and on segment $2(0.16-0.52)$. The distribution of phytoplankton in North Sunter Reservoir is uniformly distributed by current and nutrients. This research serves as an adjunctive decision-making factor over the appropriate follow-up management methods.
\end{abstract}

\section{Introduction}

The North Sunter Reservoir is an artificial reservoir located in Papanggo Village, Tanjung Priok, North Jakarta with an area of $\pm 32 \mathrm{Ha}$, a depth of $3.9 \mathrm{~m}$, and located at a height of 2 meters above sea level. The population around the reservoir amounted to 45.778 inhabitants. North Sunter Reservoir includes a blue open zone that serves to collect rainwater, drain wastewater, and tidal controllers [1]. The water source of the reservoir comes from the drainage channel, Kali Sunter, rainwater, and seawater. Therefore, the North Sunter Reservoir is a transition zone where freshwater and seawater ecosystems are interrelated. The mixing of nutrient-rich, cloudy river water inputs with poorly nutrient seawater and wind has a strong impact on the distribution of the phytoplankton community [2].

Use the land around the North Sunter Reservoir as residential, shops, offices, schools, urban forests, and toll roads. With the many activities that exist around the reservoir, the water conditions of the reservoirs are affected and decline that impact on the balance of the ecosystem and this ecosystem is under intense anthropogenic pressure that affect the reservoir to become eutrophic [3]. The diversity of freshwater phytoplankton in 540 waters stated that environmental factors surrounding the waters were the main drivers of the composition of phytoplankton species [4].
Monitoring using the phytoplankton bio indicator is more assertive in describing the decrease in the quality of the performances and is directly affected in the long run. The ability to monitor phytoplankton rapidly and in situ can help monitor water quality of a waters and observe how phytoplankton respond to changes in water conditions in the short term [5]. Seasonal phytoplankton community has been widely studied, but studies that address the vertical distribution of phytoplankton with the effect of depth differences and nutrients are still scarce [6]. Vertical distribution of phytoplankton depends essentially on the admixture of input into the waters and the movement of phytoplankton [7].

As one of the water bodies located in the coastal Jakarta, has never conducted research in this waters. This study aims to determine the condition of the waters of the North Sunter Reservoir through the distribution pattern of phytoplankton and the influence of the physical and chemical aspects of the waters on the presence of phytoplankton. Eventually, it can help the government to make the decision of the appropriate and appropriate targeted environmental management methods.

\section{Research methodology}

The study was conducted from August 2017 to January 2018 at North Sunter Reservoir. Water and phytoplankton sampling was performed 3 times at two-

\footnotetext{
* Corresponding author: dianahendrawan@trisakti.ac.id
} 
month intervals. The phytoplankton samples were taken vertically on 2 different segments, each with a depth of

Equipment and materials used are water sampler with volume 2L, plankton net no. 25, secchi disk, spectrophotometer, turbid meter, binocular microscope, counting chamber, and formalin $4 \%$. Observations and identification were conducted at the Integrated Environmental Management Unit of the Regional Environmental Laboratory (UPT LLHD) Jakarta and Unilab Perdana.

The distribution pattern analysis is based on the value of abundance, diversity, everness, and dominance with the help of Surfer 13.3.493 for Windows.

\subsection{Abundance of phytoplankton}

The determination of phytoplankton abundance was performed based on Sedgwick Rafter Couter Cell [8].

$$
N=(x / y) x(1 / v) x z
$$

$N=$ abundance of phytoplankton; $x=$ the volume of filtered water; $y=$ water volume per 1 drop; $v=$ water volume filtered; $z=$ number of individuals found.

\subsection{Diversity index}

The equation used in calculating this index is the Shannon-Wiener equation [9].

$$
H^{\prime}=\sum(n i / N) x[\ln (n i / N)]
$$

$H^{\prime}=$ diversity index; $n i=$ number of individual types $\mathrm{i}$; $N=$ total individuals.

The index value of diversity can be categorized as follows :

a) $\mathrm{H}^{\prime}<1$ : unstable biota community, low diversity

b) $1<\mathrm{H}^{\prime}<3$ : stable biota community, medium diversity

c) $\mathrm{H}^{\prime}<3 \quad$ : stable biota community, high diversity

\subsection{Everness index}

To know the difference type of spreading phytoplankton was used value of index of uniformity [10].

$$
E=H /(\ln s)
$$

$E=$ everness index; $s=$ number of genera; $\mathrm{H}^{\prime}=$ diversity index.

The value of everness ranges from $0-1$ that means :

a) $\mathrm{E}<0,5=$ biota everness is low, the wealth of each type is much different

b) $\mathrm{E}>0,5=$ biota everness is relatively even

\subsection{Dominance index}

The value of the dominant index to determine whether or not the type of phytoplankton dominates a water [10].

$$
C=\left[\sum(n i / N)^{2}\right]
$$

0-1.95 meters and 1.95-3.9 meters at 12 points.

$C=$ dominance index; $n i=$ number of individual types $\mathrm{i}$;

$N=$ total individuals; $n=$ number of genera

The dominant value ranges from $0-1$ that means :

a) $\mathrm{E}<0,5=$ no dominant biota, the community relatively stable

b) $\mathrm{E}>0,5=$ there are dominant biota, unstable communities, and stress

\section{Results and discussion}

\subsection{Phytoplankton type composition}

The percentage of phytoplankton composition based on its class from all research points can be seen in Fig 1.

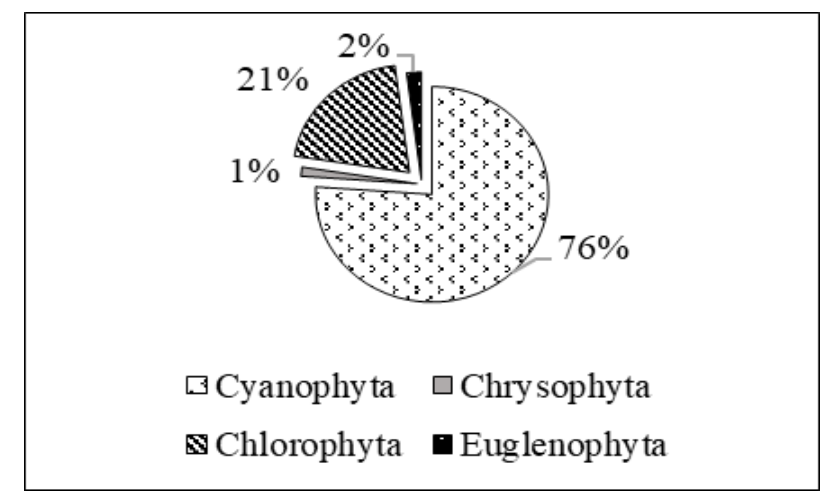

Fig. 1. Percentage of Phytoplankton Composition by Class.

A total of 35 phytoplankton species were identified during the study. Cyanophyta was represented by 7 , Chlorophyta by 9 , Chrysophyta by 15 , and Euglenophyta by 4 . The types of phytoplankton found in the North Sunter Reservoir consist of classes of Cyanophyta, Chlorophyta, Chrysophyta, and Euglenophyta. The type of phytoplankton that dominates the waters is Cyanophyta with a percentage of $76 \%$ (Fig. 1). They utilize nutrient nitrate and phosphate to compete and dominate the waters [11]. In some cases, each light depth at some point belongs to a different group probably because of the different distribution of water masses on the surface and low depth of low light at that point [12].

\subsection{Structure of the phytoplankton community}

\subsubsection{Abundance of phytoplankton}

The results of the abundance analysis for each segment of phytoplankton at North Suter Reservoir ranged between 7,104-219,820 cell/L and 6,438-132,313 cell/L. The high abundance is influenced by the high concentration of nitrate and phosphate entering the water, although the light depth only reaches until $25 \mathrm{~cm}$ depth. Waters with dim light can increase the productivity of phytoplankton and perform photosynthesis [13]. The vertical distribution of phytoplankton was basically controlled by the relative 
concentration of nitrate and phospate [6]. Overall, the concentration of phospate fund nitrate range from 4.39$14.86 \mathrm{mg} / \mathrm{L}$ and $6.50-22.91 \mathrm{mg} / \mathrm{L}$. The distribution pattern of phytoplankton abundance for each segment can be seen in Fig 2.

Based on Fig 2, the distribution pattern of phytoplankton abundance is spread evenly throughout the reservoir. The highest abundance in first segment is at point $12(219,820$ cells/ L) which is an inlet and the lowest abundance in second segment is at point 12 $(6,438$ cells/L). The high value of abundance only centered around point 12 . This condition is caused by the existence of a pile of mud excavations that block the spread of phytoplankton by the current [14]. Wind and circulation in waters also affect the distribution of nutrients and phytoplankton organisms [15]. Because the big amount of phytoplankton that found, the waters causes blooming algae.

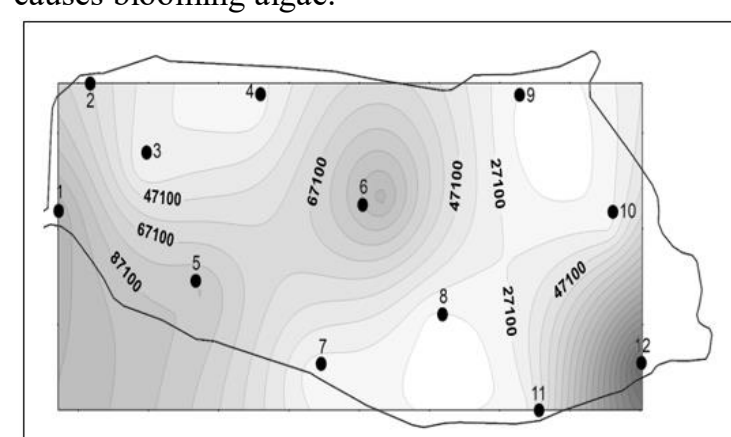

(a)

\subsubsection{Phytoplankton diversity}

The value of the phytoplankton diversity of each segment in the North Sunter Reservoir ranged between 1.22-2.39 and 1.14-2.13 respectively. The distribution pattern of the phytoplankton diversity for each segment in the North Sunter Reservoir can be seen in Fig 3.

According to Fig 3, the distribution patterns of phytoplankton diversity spread randomly from the northeast and south of the reservoir (inlet). The highest diversity in first segment is at point 9 (2.39) which is an inlet and the lowest abundance in second segment is at point 5 (1.14). The value of phytoplankton diversity is within the range of $1<\mathrm{H}^{<}<3$, which means that the waters are in stable condition and the degree of diversity distribution is medium, with $12-18$ species of phytoplankton.
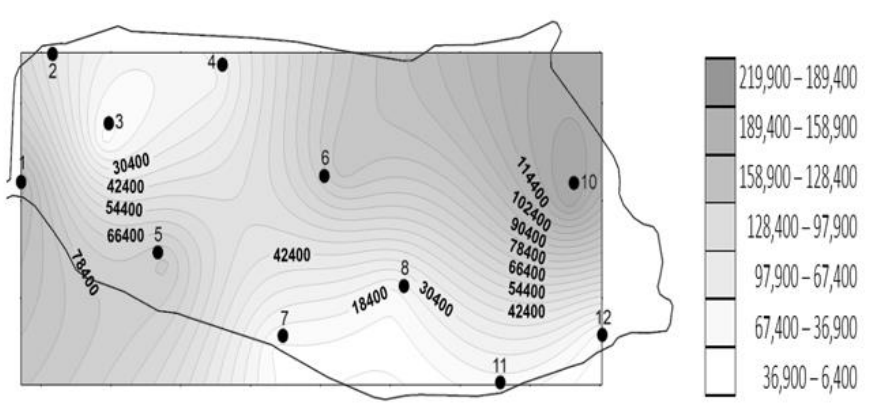

(b)

Fig. 2. Distribution pattern of phytoplankton abundance in a) first segment and b) second segment in North Sunter Reservoir.

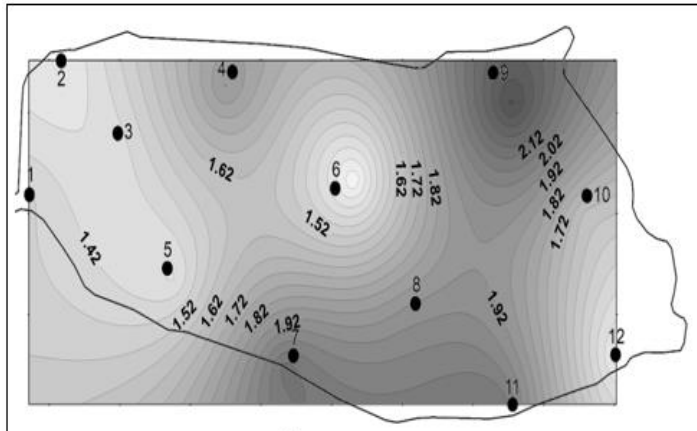

(a)

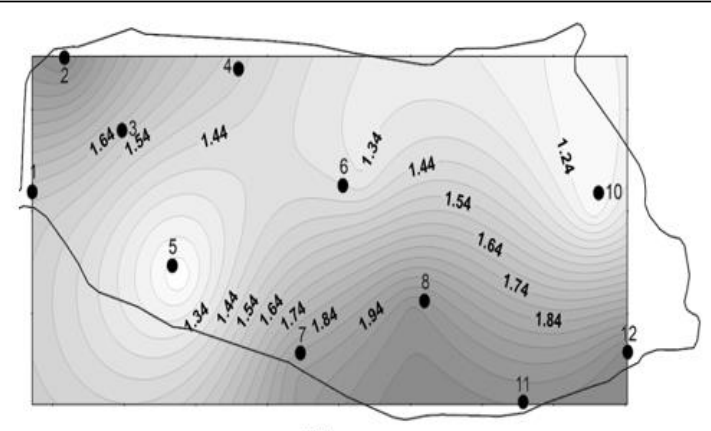

(b)

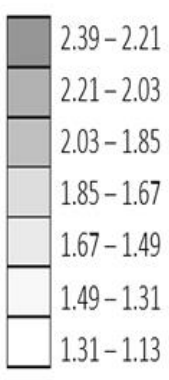

$1.31-1.13$

Fig. 3. Distribution pattern of phytoplankton diversity in a) first segment and b) second segment in North Sunter Reservoir.

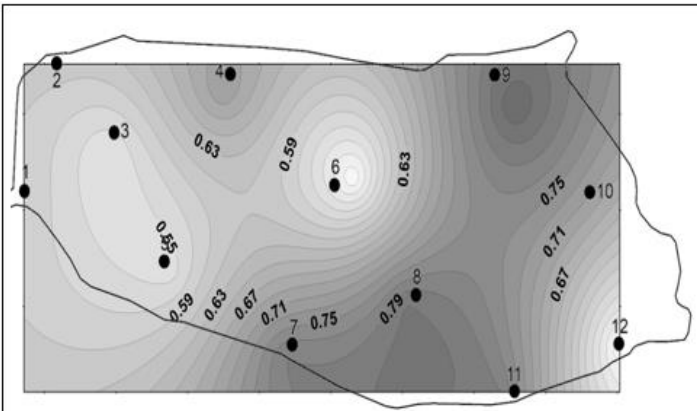

(a)

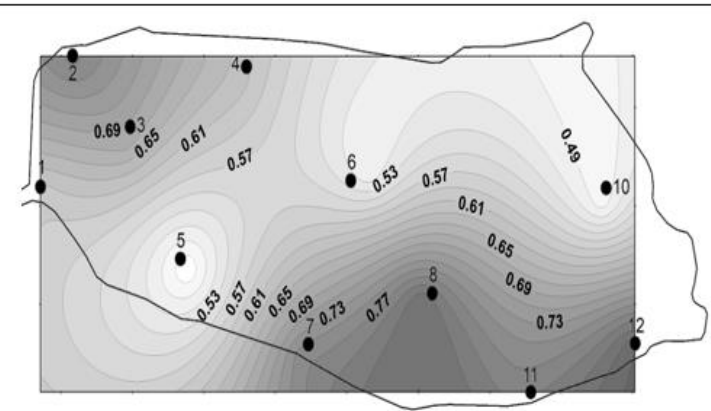

(b)

Fig. 4. Distribution pattern of phytoplankton everness in a) first segment and b) second segment in North Sunter Reservoir. 


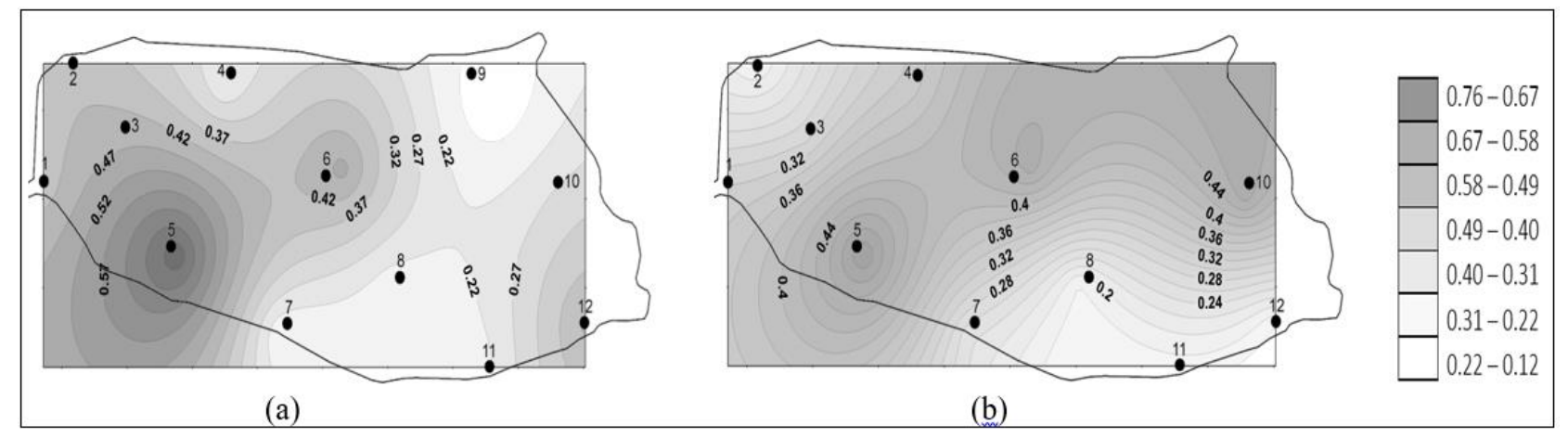

Fig. 5. Distribution pattern of phytoplankton dominance in a) first segment and b) second segment in North Sunter Reservoir.

\subsubsection{Phytoplankton everness}

The value of phytoplankton everness in the North Sunter Reservoir ranged between 0.47-0.85 and 0.45-0.85, respectively. The distribution pattern of the phytoplankton everness for each segment in the North Sunter Reservoir can be seen in Fig 4.

According to Fig 3 and Fig 4, the diversity and everness index of phytoplankton have the same pattern of distribution. The highest everness is found in first segment inlet and second segment inlet, is at point 9 $(0.85)$ and point $12(0.85)$, while the lowest everness in second segment is at point $5(0.45)$. Overall the value of phytoplankton everness describes that the waters in unstable and stable conditions, but tends to be stable (evenly) and there is no striking difference about the number of phytoplankton at each point. Big amount of everness showed that phytoplankton utilize nutrients for life [6].

\subsubsection{Phytoplankton dominance}

The index value of phytoplankton dominance in North Sunter Reservoir ranged between 0.12-0.76 and 0.160.52 , respectively. The pattern of distribution of the phytoplankton dominance for each segment in the North Sunter Reservoir can be seen in Fig 5.

Based on Fig 5, the distribution pattern of phytoplankton dominance is spread evenly throughout the reservoir. The highest and lowest dominance is in first segment on point $5(0.76)$ and point $9(0.12)$. Overall, the value of phytoplankton dominance index describes the waters is in unstable until stable conditions, but tends to be stable. This indicates that almost no species dominate the waters although certain phytoplankton species always appear in every observation [16]. The abundance of each type of phytoplankton that always appears in each observation is also not too much.

\section{Conclusion}

Composition of phytoplankton found in North Sunter Reservoir of 4 phyla are Cyanophyta, Chlorophyta, Chrysophyta, and Euglenophyta. The overall abundance of phytoplankton ranged from 6.438 to 2219.820 cells / $\mathrm{L}$ with an evenly distributed distribution pattern. The diversity $\left(\mathrm{H}^{\prime}\right)$ and everness (E) of phytoplankton ranged from 1.14-2.39 and 0.45-0.85 indicates stable water conditions and randomly shaped distribution patterns. The dominance index (D) ranges from 0.12-0.76 indicating that there is no type of phytoplankton dominating the waters in the form of uniformly distribution patterns.

\section{References}

1. Anonim. Regional Regulation of DKI Jakarta No. 01 of 2014 on Spatial Detail Plan and Zoning Regulation. (2014).

2. Suchismita S, Ji YK, Punyasloke B, Saroja KB, Pradipta RM, Rabindro NS, Ajit KP, Gurdeep R. Spatiotemporal Distribution and Composition of Phytoplankton Assemblages in a Coastal Tropical Lagoon: Chilika, India. Environ Monit Assess 187. 47 p. (2015)

3. McGlathery KJ, Sundback K, Anderson IC. Euthropication in Shallow Coastal Bays and Lagoons : The Role of Plants in The Coastal Litter. Marine Ecology Progress Series 348. 1 - 12 p. (2007)

4. Stomp M, Huisman J, Mittelbach GG, Litchman E, Klausmeier CK. Large Scale Biodiversity Patterns in Freshwater Phytoplankton. Ecology 92 (11). 2096 - 2107 p. (2011)

5. See JH, Campbell L, Richardson TL, Pinckney JL, Shen R. Combining New Technologies For Determination of Phytoplankton Structure in The Northern Gulf of Mexico. J Phycol 41. 305 - 310 p. (2005)

6. Kemal C and James S. The Vertical Distribution of Phytoplankton Assemblage of Lake James, North Carolina in Relation to Mixing Depth and Nitrate and Phosptae Concentrations. Ohio J Science 106 (4). 136 - 145 p. (2006)

7. Reynolds CS, Thompson JM, Ferguson AJD, Wiseman SW. Loss processes in the population Dynamics of Phytoplankton Maintained in Closed Systems. J Plankton Res 4 (5). 561 - 600 p. (1982)

8. American Public Health Association. Standard Methods for the Examination of Water and Wastewater. 21. 3 - 42 p. (2005). 
9. J. Basmi. Planktonologi: Plankton As Bioindicator of Water Quality. (2000).

10. E. P. Odum. Fundamentals of Ecology $5^{\text {th }}$ Edition. (2004).

11. Buchan A, LeCleir GR, Gulvik CA, Gonzalez JM. Master Recycles: Features and Fuctions of Bacteria Associated With Phytoplankton Blossom. Nat Rev Micro 12 (10). 686 - 698 p. (2014)

12. Sang HL, Hans-Uwe D, Yunsook K, Eun JC, SungHo K, Chang-Keun K. Spatial Distribution of Small Phytoplankton Composition in The Chukchi Sea. Polar Biol 37. 99 - 109 p. (2014)

12. Malinsky RN, Berman T, Berner T, Yacobi YZ, Dubinsky Z. Physiological Characteristics of Picophytoplankton, Isolatrd From Lake Kinnerer. J Plankton Res 22 (1). 63 - 76 p. (2002)

13. M. Simanjuntak. Relation of Chemical Environmental Factor, Physics to Plankton Distribution in Bangka Belitung Timur Waters, Bangka Belitung. Jurnal Perikanan XI (1). 31 - 45 p. (2009).

14. Samsidar, M. Kasim, Salwiyah. Community Structure and Distribution of Phytoplankton in Rawa Aopa Subdistrict of Angata Regency of South Konawa. Jurnal Mina Laut Indonesia 02 (06). 109 119 p. (2013).

15. Peter N. Phytoplankton Distribution and Abundance Along Zanzibar and Pemba Channels. Thesis. University of Dar es Salaam. Tanzania. 105 p. (2013)

16. Enrique MO, Luiz CP, Ana B, D Glen G. The Spatial Distribution of Different Phytoplankton Functional Groups in A Mediterranian Reservoir. Aquat Ecol 42. 115 - 218 p. (2008) 